\title{
Fenretinide Derivatives Act as Disrupters of Interactions of Serum Retinol Binding Protein (sRBP) with Transthyretin and the sRBP Receptor
}

\author{
José Angel Campos-Sandoval, ${ }_{\S}$ Clara Redondo, ${ }^{\ddagger}$ Gemma K. Kinsella, ${ }^{\dagger}$ Akos Pal, ${ }^{\dagger}$ Geraint Jones, ${ }^{\S}$ \\ Gwen S. Eyre, ${ }^{\S}$ Simon C. Hirst, ${ }^{\S}$ and John B. C. Findlay ${ }^{*,+, \neq}$ \\ ${ }^{\dagger}$ The Marie Curie Laboratory for Membrane Proteins, Department of Biology, National University of Ireland, Maynooth, \\ County Kildare, Ireland \\ ${ }^{\ddagger}$ School of Biochemistry and Molecular Biology, University of Leeds, Leeds LS2 9JT, U.K. \\ ${ }^{\S}$ Sygnature Chemical Services Limited, BioCity, Pennyfoot Street, Nottingham NG1 1GF, U.K. \\ Supporting Information
}

ABSTRACT: Serum retinol binding protein (sRBP) is released from the liver as a complex with transthyretin (TTR), a process under the control of dietary retinol. Elevated levels of sRBP may be involved in inhibiting cellular responses to insulin and in generating first insulin resistance and then type 2 diabetes, offering a new target for therapeutic attack for these conditions. A series of retinoid analogues were synthesized and examined for their binding to $s R B P$ and their ability to disrupt the $s R B P-T T R$ and $s R B P-s R B P$ receptor interactions. A number inhibit the sRBP-TTR and sRBP-sRBP receptor interactions as well as or better than Fenretinide (FEN), presenting a potential novel dual mechanism of action and perhaps offering a new therapeutic intervention against type 2 diabetes and its development. Shortening the chain length of the FEN derivative substantially abolished binding to sRBP, indicating that the strength of the interaction lies in the polyene chain region. Differences in potency against the $s R B P-T T R$ and $s R B P-s R B P$ receptor interactions suggest variant effects of the compounds on the two loops of sRBP guarding the entrance of the binding pocket that are responsible for these two protein-protein interactions.

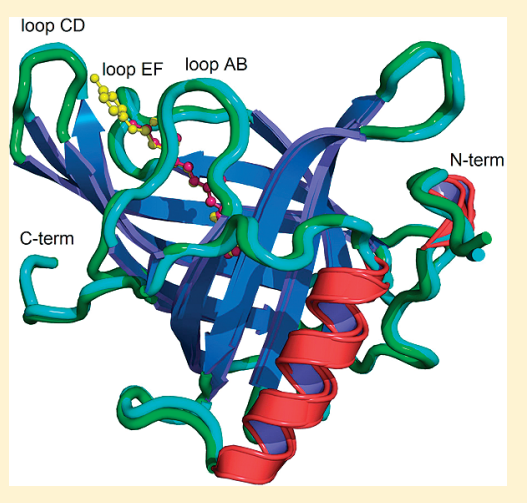

\section{INTRODUCTION}

Transport of retinol $[\mathrm{ROH}$ (Figure 1)] in the blood is controlled by the lipocalin serum retinol binding protein ( $\mathrm{sRBP}, 21 \mathrm{kDa}$ ), which is synthesized and released from the liver as a complex with a second protein, transthyretin (TTR). ${ }^{1-3}$ sRBP consists of an $\mathrm{N}$-terminal coil, eight antiparallel $\beta$-strands $(\mathrm{A}-\mathrm{H})$ forming a barrel, and a short $\alpha$-helix close to the C-terminus [Protein Data Bank (PDB) entry $1 \mathrm{RBP}^{4}$ ]. ${ }^{1} \mathrm{ROH}$ is accommodated in the barrel with the $\beta$-ionone ring positioned innermost, the polyene chain fully extended, and the hydroxyl end group nearly solvent-exposed near the $A-B, C-D$, and $E-F$ loops (Figure 1). Circulating in the plasma, sRBP is bound to TTR, a homotetramer of $\sim 56 \mathrm{kDa}$. Each TTR monomer consists of eight antiparallel $\beta$-strands $(\mathrm{A}-\mathrm{H})$ arranged like a Greek key $\beta$-barrel. One tetramer of TTR can bind two sRBP molecules in vitro; ${ }^{5}$ however, because of a significantly higher concentration of TTR compared to that of sRBP, each tetramer forms a $1: 1$ complex in plasma. ${ }^{6}$ This association of the sRBP-ROH complex with TTR is believed to prevent its filtration through the kidney glomeruli. ${ }^{3}$ In the blood, the uncomplexed or free form of sRBP interacts with a receptor in the plasma membrane of virtually all cells in a $\mathrm{ROH}$-sensitive manner. ${ }^{7,8}$ Only the TTRdissociated holo-sRBP is able to bind to the receptor with high affinity, because of steric hindrance of access to the sRBP - sRBP receptor binding site. ${ }^{7-10}$ Binding of sRBP to its receptor is followed by the release of retinol and its uptake into the cell via the sRBP receptor.

A notable paper ${ }^{11}$ has chronicled the evidence of the involvement of sRBP in obesity, insulin resistance, and type 2 diabetes. The level of sRBP is elevated in insulin resistant mice and humans with obesity and type 2 diabetes. ${ }^{12}$ sRBP is mostly secreted by the liver but can also come from other tissues, including adipocytes. ${ }^{13}$ The source of this excess sRBP is thought to be visceral adipose tissue, hence the link to obesity. sRBP acting on peripheral tissues such as skeletal muscle is postulated to attenuate insulin sensitivity, as indicated by reduced IRS1 phosphorylation and PI3K activity. ${ }^{11}$ The mechanism of this proposed effect is unknown but should involve a sRBP-binding entity of some kind.

Fenretinide [4-hydroxy(phenyl)retinamide (FEN) (Figure 1)] is a synthetic retinoid and has been investigated for potential use in the treatment of cancer, cystic fibrosis, rheumatoid arthritis, acne, psoriasis, and Stargardt's disease. ${ }^{14,15}$ Previously, FEN has

Received: November 26, 2010

Published: May 18, 2011 

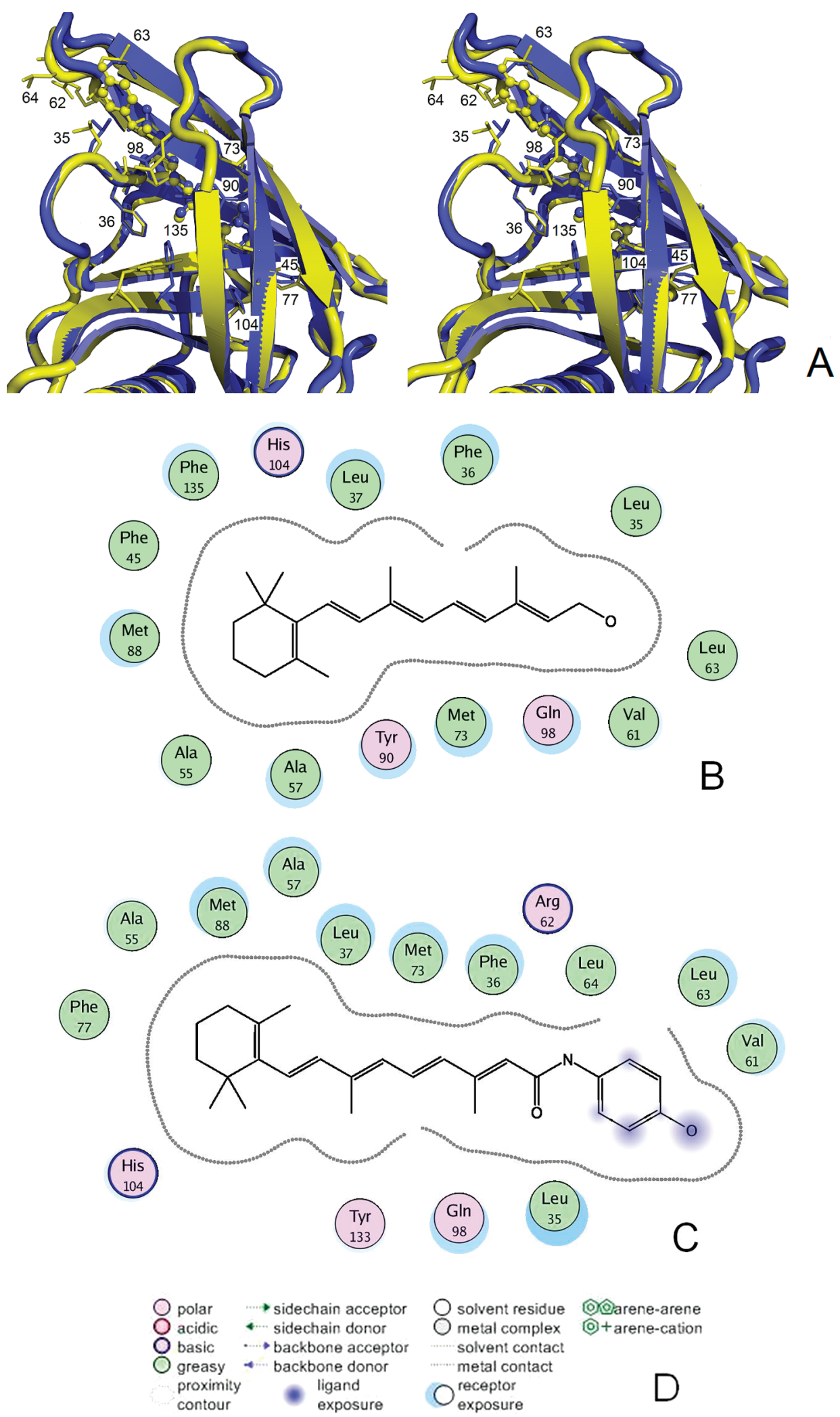

Figure 1. (A) Three-dimensional image of ROH (blue) in sRBP (PDB entry $1 \mathrm{RBP}^{4}$ ) and FEN (yellow) in sRBP (PDB entry $\left.1 \mathrm{FEL}{ }^{16}\right)$ with contacting residues labeled and illustrated in stick format. Images are shown with a $6^{\circ}$ rotation around the $y$ axis. Images produced using Pymol. ${ }^{39}$ (B and C) Twodimensional (2D) depiction of $\mathrm{ROH}$ and FEN binding poses as depicted using $\mathrm{MOE}^{20}$ (D) Legend for the $2 \mathrm{D}$ interactions in the binding pose as depicted using MOE.

been shown to compete with retinoids for binding to sRBP (PDB entry 1FEL), ${ }^{16}$ disrupting sRBP-TTR complexes and resulting in urinary secretion of sRBP and systemic depletion of $\mathrm{ROH}^{17}$ Administration of FEN has been observed to exert therapeutic 
effects in mouse models of obesity and diabetes. ${ }^{15}$ Long-term FEN treatment prevents high-fat diet-induced obesity, insulin resistance, and hepatic steatosis. ${ }^{18}$

The hypothesis we are exploring is that agents that reduce sRBP levels or disrupt the protein interactions that sRBP undergoes will prevent the genesis of insulin resistance and consequently that of type 2 diabetes. In this work, we developed a series of retinoid analogues that were first evaluated experimentally for binding to sRBP through fluorescence measurements. Subsequently, their ability to disrupt protein - protein interactions was examined through pull-down, timeresolved fluorescence resonance energy transfer (TR-FRET) and surface plasmon resonance (SPR) assays of sRBP-TTR complexes and SPR assays of sRBP with solubilized membranes containing the sRBP receptor. The latter is a novel focus in an effort to identify compounds that exhibit a dual or different effect. Compounds that exhibit differences in their ability to inhibit sRBP-TTR and sRBP-sRBP receptor interactions may provide an approach to examining both the validity and the mechanism of action of sRBP levels in the context of insulin resistance and type 2 diabetes.

\section{RESULTS}

Retinoid Analogues. We were largely interested in establishing if the retinoids could bind to SRBP without necessarily penetrating deep into the binding pocket. We also wished to investigate the level of variability allowed at the region of the molecule near the entrance to the binding cavity, thought to be the effective moiety with regard to alterations in conformation. We were also interested in determining if steric hindrance was the sole and main mechanism for inhibition or whether a conformational change was also required.

Traditional medicinal chemistry around both ends of a known chemical scaffold ( $\mathrm{ROH} / \mathrm{FEN}$ ) was utilized to develop a novel series of retinoid analogues (Figure 2). The target compounds 1-68 were prepared as outlined in Schemes 1-3 (see Experimental Section), and all chemical structures are shown in the Supporting Information.

The approach of the analysis of these compounds was structured on three levels. The first binding to sRBP was monitored using quenching of the fluorescence of the intrinsic tryptophan in SRBP and/or inhibition of the FRET response of

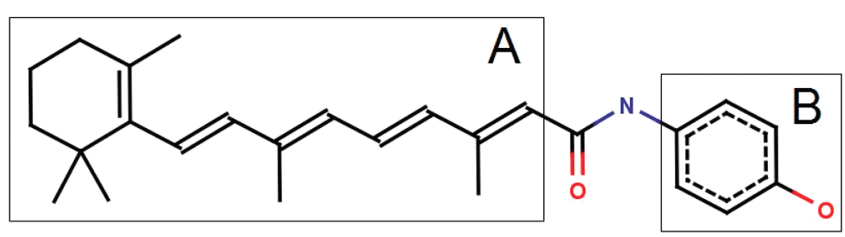

Figure 2. 2D image of Fenretinide (FEN), which differs from ROH by a phenylamide in place of the hydroxyl group. (A) Area where the variations were introduced at the $\beta$-ionone ring end of FEN (compounds 2-22). (B) Polyene end of FEN where variations were introduced (compounds 1 and 23-68). bound retinol. The second involved the SRBP-TTR interaction as monitored by pull-down and SPR responses. The third monitored sRBP-sRBP receptor interactions in solubilized membrane preparations using SPR. Only compounds that provided some evidence of binding to sRBP progressed to the second and third stages.

Binding of Compounds to sRBP. To study the interaction between retinoid analogues and sRBP, the quenching of the intrinsic tryptophan ( $\operatorname{Trp}$ ) fluorescence of the apoprotein following excitation at $280 \mathrm{~nm}$ was measured in the presence of increasing concentrations of the compounds. $\mathrm{ROH}$ binds to the ligand binding site of the sRBP and produces a quenching of the Trp fluorescence. Those compounds that absorbed in the emission region of Trp reduced this emission in a dose-dependent manner, indicative of their specific interaction with aposRBP (Figure 3). The fluorescence intensities of the compounds in an $\mathrm{N}$-acetyltryptophanamide solution were measured to correct the titration curves. The change in fluorescence intensity was used to calculate the apparent dissociation constants $\left(K_{d}\right)$ for the protein-compound interactions as described by Cogan et al. ${ }^{19}$ The $K_{\mathrm{d}}$ values for selected compounds are listed in Table 1 . A $K_{d}$ of $182 \pm 4 \mathrm{nM}$ was obtained for the ROH-sRBP complex, in agreement with that reported in the literature for the protein isolated from human plasma. ${ }^{19}$ The other compounds had an affinity in the same range (Table 1).

Effect of Compounds on the sRBP-TTR Interaction Determined by a Pull-Down Assay. The ability of the 68 library compounds to disrupt the interaction between sRBP and its partner, TTR, was first examined using a pull-down assay. The purified ROH-sRBP-TTR complex, as indicated in Experimental Section, was utilized. Both proteins were incubated together in the presence of $\mathrm{ROH}$ and the various compounds, at 10 and $100 \mu \mathrm{M}$, respectively. The difference in concentration between $\mathrm{ROH}$ and the compounds allowed for the detection of their inhibitory effect. After incubation with the different compounds, the flow-throughs were run in SDS gels and the free sRBP disrupted from the complexes was detected by silver staining. A representative result for $\mathrm{ROH}$ and FEN is shown in Figure 4A. FEN, which is known to disrupt the interaction between SRBP and TTR, was used as a control to which potential positive compounds could be compared. A small quantity of free sRBP was always obtained in the negative control flow-through (no compound added), as a consequence of the relatively weak interaction $\left(K_{\mathrm{d}} \approx 0.3 \mu \mathrm{M}\right)$ between the two proteins. ${ }^{21} \mathrm{FEN}$ produced an estimated 3-5-fold increase in the amount of sRBP released from the complex. The shorter retinoid analogues, 2-22, which did not exhibit absorption in the Trp emission region, also did not show the ability to disrupt the sRBP-TTR interaction and were disregarded in further studies. A number of compounds based on scaffold B (1 and 23-68) showed a similar disruptive effect on the complex with FEN. The dose-dependent effect of the positive compounds was similarly assessed using increasing concentrations of the analogues, as shown for one selected compound, $\mathbf{5 8}$ (Figure 4B).

\section{Scheme 1}<smiles>CC1=C(/C=C/C(C)=C/C=C/C(C)=C/C(=O)O)C(C)(C)CCC1</smiles><smiles>COC(=O)COc1ccc(N)cc1</smiles>

$\mathrm{EDCl}$<smiles>COC(=O)COc1ccc(NC(=O)/C=C(C)/C=C/C=C(C)/C=C/C2=C(C)CCCC2(C)C)cc1</smiles> 
sRBP-TTR Interaction Assessed by TR-FRET. To estimate the potency of the different inhibitors selected in the pull-down assay, we continued our analysis of the compounds using a TRFRET assay based on a methodology developed previously. ${ }^{22}$ The sRBP used in this assay was a recombinant protein expressed with a His tag in Pichia pastoris, ${ }^{23}$ to which an europium antiHis antibody was bound. Native TTR was labeled with biotin. When both proteins bind, and after excitation of europium with light at $340 \mathrm{~nm}$, energy is transferred from europium to streptavidin-conjugated allophycocyanin (APC) and the emission of light can be detected at $665 \mathrm{~nm}$. A stronger signal is observed as the affinity between both proteins increases with $\mathrm{ROH}$ concentration. The TR-FRET signal was measured against increasing concentrations of $\mathrm{ROH}$ and a constant concentration of inhibitor. The system was tested first with FEN from 0.1 to $50 \mu \mathrm{M}$, and from this experiment, an appropriate concentration of $10 \mu \mathrm{M}$ was selected to study the inhibitory effect of the compounds. A set of $\mathrm{ROH}$ dose-response curves in the presence of inhibitory compounds is shown in Figure 5. The compounds demonstrated a competitive antagonist effect, as previously shown for FEN, ${ }^{22}$ with a shift of the $\mathrm{ROH}$ response curve to the right. FEN produced a 30 -fold increase in the $\mathrm{EC}_{50}$ (Table 2). Additionally, compounds $\mathbf{1}$ and $\mathbf{5 8}$ had a strong effect, with a 15 -fold increase, while the rest of the compounds tested in the TR-FRET assay produced an only slight increase in the $\mathrm{EC}_{50}$ (2-3-fold).

sRBP-TTR Interaction Assessed by Surface Plasmon Resonance. We sought to further expand our understanding of the best retinoid analogues by studying their ability to disrupt the interaction between sRBP and TTR in real time using a surface plasmon resonance (SPR) assay. As shown in Figure 6, the only compound that strengthens the interaction between sRBP and TTR is ROH, as expected. None of the analogues strengthened the interaction with TTR, but all of them, with the exception of compound 1, were less disruptive than FEN itself and hence exhibited qualitatively the same results that were seen in the TR-FRET analysis.

sRBP-Receptor Interaction Assessed by Surface Plasmon Resonance. The ability of the compounds to disrupt the interaction between sRBP and solubilized membranes was also examined using the SPR binding assay. Detergent-treated HEK293 membrane fractions were preincubated with compounds and then injected over SRBP immobilized on the sensor chip surface. All the novel retinoid compounds tested had a negative effect on the stability of the $\mathrm{SRBP}$ - membrane protein complex and consequently produced faster dissociation (Figure 7). However, FEN had little or no effect. All experiments were repeated at least three times with no significant differences. Note that background binding to other components of the solubilized membrane will be present.

\section{DISCUSSION}

For some time, there has been great concern about the link among obesity, insulin resistance, type 2 diabetes, and cardiovascular disease. A recent scientific discovery provided a way forward toward preventing the avalanche of disability due to type 2 diabetes. This was the observation that elevated sRBP levels may attenuate the response of the cell to insulin, thus increasing resistance and presaging type 2 diabetes. ${ }^{11} \mathrm{~A}$ second important element was the much earlier demonstration and functional characterization of a plasma membrane receptor for $\mathrm{sRBP}^{24,25}$ through which the effects of sRBP might be mediated. The connection with insulin action is a novel one, suggesting cross talk between RBP and insulin, because higher levels of the former are seen to inhibit the intracellular response to insulin. ${ }^{13}$

There has been some controversy about whether sRBP levels are statistically correlated with the development particularly of type 2 diabetes, with reports both confirming ${ }^{26-29}$ and failing to confirm ${ }^{30-32}$ the link. The reasons for these differences are not clear, the only suggestion put forward so far being some variation in the methodologies used for sRBP estimation, ${ }^{29}$ but very significantly, the first studies on isolated human adipocytes confirmed that an elevated sRBP level

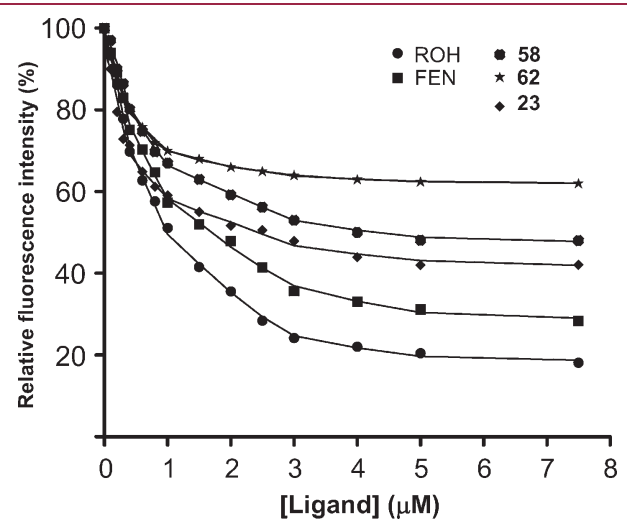

Figure 3. Titration of apo-sRBP with a selection of compounds. For quenching of the protein fluorescence, the excitation and emission wavelengths were 280 and $345 \mathrm{~nm}$, respectively. The titration system consisted of $0.5 \mathrm{~mL}$ of $2 \mu \mathrm{M}$ purified apo-sRBP in PBS ( $\mathrm{pH} 7.4$ ). Solutions of ROH, FEN, or compounds in ethanol were added to the cuvette until a final concentration of $7.5 \mu \mathrm{M}$ was reached. The curves were corrected for the inner filter effect of the compounds.

Scheme 2
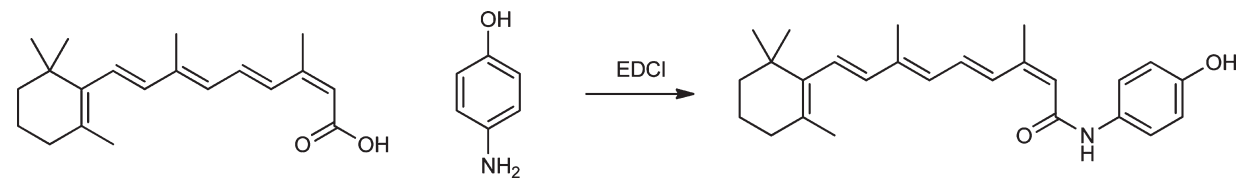

Scheme 3<smiles>CC1=C(/C=C/C(C)=C/C=C/C(C)=C/C(=O)O)C(C)(C)CCC1</smiles>

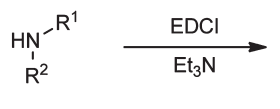

4381<smiles>[R]N(C)C(=O)/C=C(C)/C=C/C=C(C)/C=C/C1=C(C)CCCC1(C)C</smiles> 
Table 1. Apparent Dissociation Constants ${ }^{a}\left(K_{\mathrm{d}}\right)$ for the Protein-Compound Interactions Calculated According to the Method of Cogan et al. ${ }^{19}$

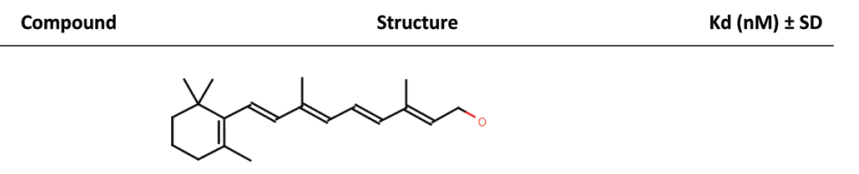

$\mathrm{ROH}$

(all-E)-3,7-Dimethyl-9-(2,6,6-trimethyl-1 cyclohexen-1-yl)-2,4,6,8-

nonatetraen-1-ol

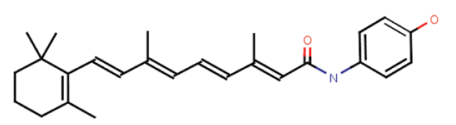

(2E,4E,6E,8E)-N-(4-hydroxyphenyl)-3,7-dimethyl-9-(2,6,6-

FEN

trimethylcyclohex-1-en-1-yl)nona-2,4,6,8-tetraenamide

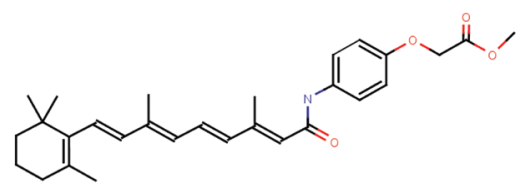

methyl 2-\{4-[(2E,4E,6E, 8E)-3,7-dimethyl-9-(2,6,6-trimethylcyclohex-1-

1

en-1-yl)nona-2,4,6,8-tetraenamido]phenoxy\}acetate

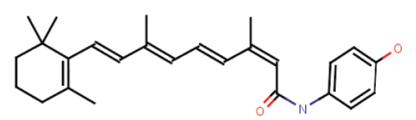

(2Z,4E,6E,8E)-N-(4-hydroxyphenyl)-3,7-dimethyl-9-(2,6,6-

23
$182 \pm 4$

$156 \pm 18$

$131 \pm 43$

$333 \pm 24$

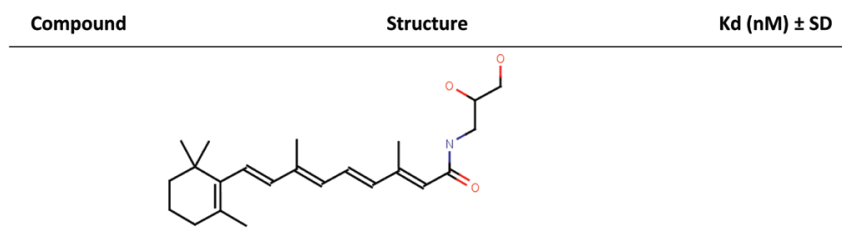

(2E,4E,6E,8E)-N-(2,3-dihydroxypropyl)-3,7-dimethyl-9-(2,6,6-

41

trimethylcyclohex-1-en-1-yl)nona-2,4,6,8-tetraenamide

$178 \pm 20$

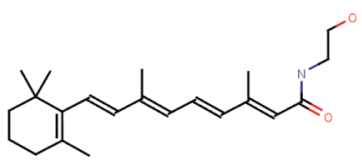

(2E,4E,6E,8E)-N-(2-hydroxyethyl)-3,7-dimethyl-9-(2,6,6-

trimethylcyclohex-1-en-1-yl)nona-2,4,6,8-tetraenamide

$214 \pm 32$

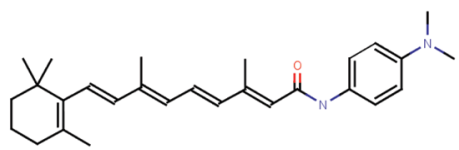

(2E,4E,6E,8E)-N-[4-(dimethylamino)phenyl]-3,7-dimethyl-9-(2,6,6-

58

trimethylcyclohex-1-en-1-yl)nona-2,4,6,8-tetraenamide

$98 \pm 21$

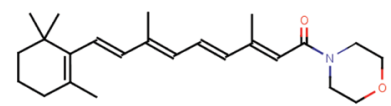

(2E,4E,6E,8E)-3,7-dimethyl-1-(morpholin-4-yl)-9-(2,6,6-

62

${ }^{a}$ Data shown are average values \pm the standard deviation (SD) from three independent experiments.

does indeed attenuate insulin-induced IRS-1 and ERKI/2 phosphorylation. ${ }^{13}$ Moreover, as found in the whole-animal studies, the serine residue on IRS-1 specifically affected was that closely identified with insulin signaling. Considering all this, it seems possible that reducing the "activity" of elevated levels of sRBP may restore normal insulin sensitivity and counteract type 2 diabetes.

The hypothesis we are exploiting is that compounds that reduce sRBP levels or disrupt its protein interactions will prevent the genesis of insulin resistance and consequently that of type 2 diabetes and its cardiovascular complications. Administration of FEN has been observed to exert therapeutic effects in mouse models of obesity and diabetes. ${ }^{15,18}$ Long-term FEN treatment prevents high-fat diet-induced obesity, insulin resistance, and hepatic steatosis. ${ }^{18}$ Additionally, retinoic acid (RA) treatment was determined to reduce body weight and basal serum glucose, serum $\mathrm{ROH}$, and sRBP levels coupled with improved insulin sensitivity and to decrease the ROH:sRBP ratio. ${ }^{33}$ In this work, a series of retinoid analogues were synthesized and examined for their ability to disrupt the interaction of sRBP with TTR and, for the first time, with its receptor. As a first step, we assessed the binding of these compounds to sRBP by fluorescence titration, a well-established method. ${ }^{19}$ The fluorescence emission data were used to calculate $K_{\mathrm{d}}$ values according to the method of Cogan et al. ${ }^{19}$ The values obtained were consistent with previous work, ${ }^{19,34}$ with a $K_{d}$ for ROH binding to sRBP of $182 \pm 4 \mathrm{nM}$ and comparable values for analogues 1 and $23-68$. This is in agreement with earlier findings, which indicated that modifications of the functional hydroxyl end group of $\mathrm{ROH}$ (see Figure 2 and schemes in Experimental Section) do not change substantially the affinity for apo-sRBP. ${ }^{17,19,35}$ Compounds 2-22 did not show any absorption in the Trp emission region, and their binding to sRBP could not be assessed by this method. It has been shown that, to interact specifically with sRBP, retinoids must possess an intact trimethylcyclohexenyl group that establishes close contacts with the side chains of the internal $\beta$-barrel cavity. ${ }^{35}$ The lack of a cyclohexene ring or having a shorter structure may limit the binding affinity of compounds 2-22 for $\mathrm{sRBP}$, indicating that the strength of the interaction lies in the polyene chain region.

In the available crystal structures, the $\mathrm{ROH}$ hydroxyl group is near the protein surface, in the region of the entrance loops surrounding the opening of the binding cavity. It participates in polar interactions and becomes fully buried in the holo-sRBPTTR complex. ${ }^{4}$ However, the cyclohexene ring and the isoprene tail of FEN take the place of the corresponding portions of $\mathrm{ROH}$, while the hydroxyphenyl amide group protrudes from the cavity toward the solvent, replacing the $\mathrm{ROH}$ hydroxyl group and a water molecule hydrogen bonded to it. ${ }^{16}$

Subsequent analysis focused on compounds 1 and 23-68 with an examination of their effect on the interaction between sRBP and TTR. For this purpose, we developed a pull-down 


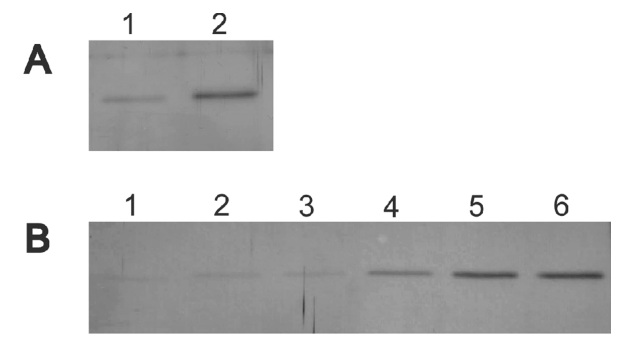

Figure 4. Pull-down assay for sRBP after incubation with compounds. (A) The ROH-sRBP-His-TTR complex was incubated in the presence of $10 \mu \mathrm{M} \mathrm{ROH}$ and $100 \mu \mathrm{M}$ FEN. After incubation, the complexes and free sRBP were separated by a pull-down assay and the flow-throughs analyzed by SDS-PAGE. Lanes reveal free sRBP in the flow-through fractions: lane 1, control (10 $\mu \mathrm{M} \mathrm{ROH}$, no compound); lane 2, $10 \mu \mathrm{M}$ retinol and $100 \mu \mathrm{M}$ FEN (positive control for complex disruption). (B) Dose-response pull-down assay for 58. Lane 1 was the control $(10 \mu \mathrm{M}$ $\mathrm{ROH}$, no compound). Lanes $2-6$ contained $10 \mu \mathrm{M} \mathrm{ROH}$ and different concentrations of $\mathbf{5 8}(1,10,20,50$, and $100 \mu \mathrm{M}$, respectively).
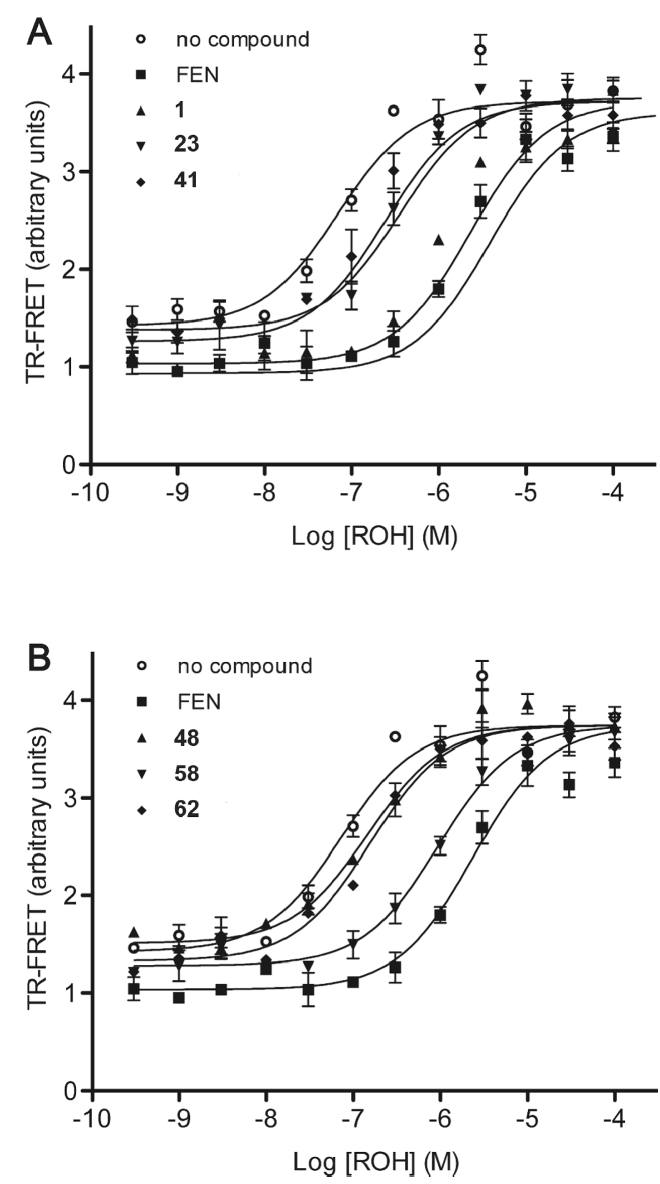

Figure 5. Time-resolved FRET for the sRBP-TTR interaction. Assays were conducted with a fixed concentration $(10 \mu \mathrm{M})$ of compound and increasing concentrations of ROH. sRBP and TTR concentrations were 5 and $100 \mathrm{nM}$, respectively. TR-FRET signals are the ratios between 665 and $615 \mathrm{~nm}$ emissions. The curves were generated using a sigmoidal dose-response equation in Prism (GraphPad Software Inc.). Results shown are from a representative experiment performed in duplicate \pm the standard deviation.

assay that could detect free sRBP released from the $\mathrm{ROH}-\mathrm{sRBP}-$ TTR complex after its disruption in the presence of compounds.
Table 2. $\mathrm{EC}_{50}$ Values for $\mathrm{ROH}-\mathrm{sRBP}-\mathrm{TTR}$ Interaction in the Presence of Compounds ${ }^{a}$

\begin{tabular}{lc}
\multicolumn{1}{c}{ compound } & $\mathrm{EC}_{50}(\mathrm{nM})$ \\
no compound & $71 \pm 11$ \\
Fenretinide & $2372 \pm 186$ \\
$\mathbf{1}$ & $1260 \pm 177$ \\
$\mathbf{2 3}$ & $245 \pm 35$ \\
$\mathbf{4 1}$ & $171 \pm 21$ \\
$\mathbf{4 8}$ & $145 \pm 5$ \\
$\mathbf{5 8}$ & $954 \pm 114$ \\
$\mathbf{6 2}$ & $154 \pm 17$
\end{tabular}

${ }^{a}$ Data shown are average values \pm the standard deviation from three independent experiments.

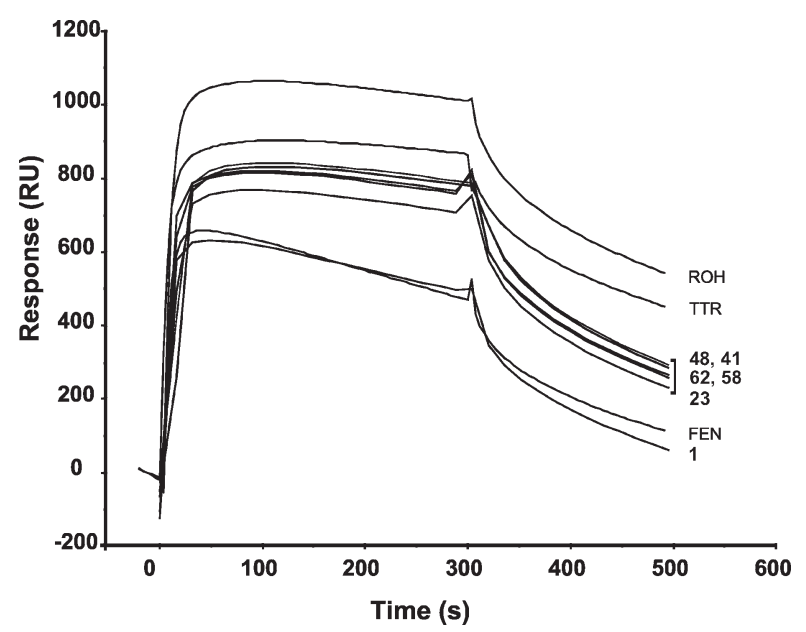

Figure 6. Sensorgram showing interactions of His-sRBP with TTR in the presence of selected compounds. SPR response curves reflect the interaction of TTR with immobilized sRBP. The responses were recorded as a function of time and are expressed in resonance units (RU).

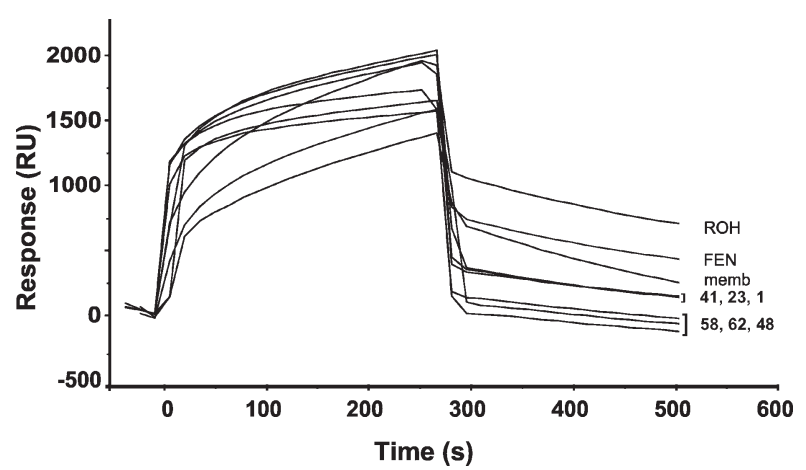

Figure 7. Sensorgram showing interactions of His-sRBP with solubilized HEK293 cell membranes in the presence of selected compounds. SPR response curves reflect the interaction of HEK293 cell solubilized membrane preparations passed over immobilized sRBP. The responses were recorded as a function of time and are expressed in resonance units (RU).

The crystal structure of holo-sRBP complexed with TTR revealed that $\mathrm{ROH}$ participates in the interaction of sRBP with $\mathrm{TTR}^{4}$ increasing the affinity of the $\mathrm{sRBP}-\mathrm{TTR}$ interaction 
6-fold, from 1.2 to $0.3 \mu \mathrm{M} .^{21}$ This relatively low affinity, even for the holoprotein, is physiologically significant: because holo-sRBP complexed with TTR lacks affinity for its membrane receptor, 9,10 a small amount of uncomplexed holo-sRBP is needed to deliver $\mathrm{ROH}$ to the cells through this specific receptor. On the other hand, FEN, with a structure similar to that of $\mathrm{ROH}$ but containing a bulky phenylamide in place of the hydroxyl group, drastically interferes with the sRBP-TTR interaction because of steric hindrance in the contact regions between sRBP and TTR and also changes in the position of the loops surrounding the entrance of the binding site. In agreement with these observations, a small amount of free sRBP was always detected in the control without compounds after incubation of the holosRBP-TTR complex in the pull-down assay. In comparison, a larger amount of free sRBP (estimated to be 3-5-fold) could be measured after incubation of the complex with FEN. Compounds 2-22 did not show the ability to disrupt the sRBP-TTR interaction and will be disregarded in further studies. However, a number of compounds based on scaffold B [with variations in the outer end (1 and 23-68)] showed a similar disruptive effect on the complex with FEN and probably act through the same mechanism. Interestingly, some of the larger groups at the polyene end of the retinoid analogues extend farther than FEN but do not disrupt the sRBP-TTR interaction, indicating that the retinoid analogues may not function solely as steric blockers but perhaps induce conformational changes in the loop regions. This shall be further examined in the crystal structure work.

We cannot calculate accurate $K_{\mathrm{i}}$ values because of the nature of the pull-down assay. In all runs (tested at least three times) of this assay, the band intensities were very similar to those for FEN, indicating a disruptive effect with a potency similar to that of FEN. From this qualitative analysis, we could draw no definitive conclusions regarding the strength of the disruption of the best analogues, and hence, additional studies were pursued to validate our initial findings. We used a TR-FRET assay, a technique that has been recently applied to the study of sRBP-TTR interactions, to characterize their inhibitory behavior. ${ }^{22}$ The selected compounds produced a decrease in the strength of the basal interaction between sRBP and TTR in the absence of ROH and a right shift of the $\mathrm{ROH}$ curve compared to the control (no compound). This is in agreement with the competitive behavior described for FEN and retinyl acetate. ${ }^{22}$ The TR-FRET results were also validated using a secondary binding assay, SPR, which yielded qualitatively similar results, with FEN and compound 1 exhibiting a more disruptive sRBP-TTR interaction effect, while the other compounds were clustered together in both assays.

With the SPR assay using the HEK293 cell membranes and immobilized His-sRBP, ROH had a positive effect on the interaction observed in real time and the compounds all had a disruptive effect, with FEN exhibiting the smallest disruption of the set. We have given values for the disruption of the $\mathrm{RBP}-\mathrm{TTR}$ interaction from FRET assays, but it is not possible to generate other than relative potencies for the $\mathrm{SBP}$ - receptor interactions because of the nature of SPR with solubilized whole membrane preparations. The usual problem is that accurate values can be obtained only when pure preparations of a receptor are used.

Using our three-tiered assay approach, including analyzing binding to sRBP and SPR studies of the sRBP-TTR and sRBP-sRBP receptor interaction, we were able to show that most sRBP binders exhibited a dual effect. Some compounds inhibited TTR more than the receptor interaction and a few the reverse. It is known that FEN reduces sRBP levels and improves insulin sensitivity, ${ }^{11,16,36}$ probably by disrupting the $\mathrm{ROH}-$ sRBPTTR complex promoting clearance of sRBP. ${ }^{1,17}$ Our SPR data suggest that FEN might have a dual effect on the RBP insulin resistance link: (i) lowering sRBP levels and (ii) interacting directly with the insulin pathway inside the cell, its uptake having been mediated by the sRBP receptor. This is supported by the observation that FEN only "mildly" interferes with the interaction of the sRBP-ROH complex with the membrane compared to the strong disruption of that interaction caused by other compounds.

\section{CONCLUSIONS}

In this work, a number of active retinoid-like molecules that inhibit $\mathrm{sRBP}-\mathrm{TTR}$ and $\mathrm{sRBP}$-receptor interactions as well as or better than FEN, the antitumor positive control, have been identified, thereby presenting a potential novel dual mechanism of action. Thus, the compounds discovered may offer a new therapeutic intervention against type 2 diabetes and its development.

\section{EXPERIMENTAL SECTION}

Biology. Materials. Escherichia coli strain BL21(DE3), P. pastoris strain $\mathrm{KM} 71 \mathrm{H}($ aox $1:: A R G 4$, arg4), expression vector $\mathrm{pPICZ} \alpha \mathrm{A}$, the Zero Blunt TOPO PCR cloning kit, and europium-labeled anti-His tag antibodies were purchased from Invitrogen. HEK293 cells (human embryonic kidney) were from the ATCC. SureLight streptavidin-conjugated allophycocyanin (APC) was from PerkinElmer. The EZ-Link Sulfo-NHS-LC-Biotinylation kit was from Pierce. ROH, FEN, native human TTR, and synthetic oligonucleotide primers were from Sigma. Polymerase chain reaction (PCR) amplification of coding sequences was performed with PfuTurbo Hotstart DNA polymerase from Stratagene. Ni-NTA superflow resin and cobalt affinity gel were purchased from Qiagen and Sigma, respectively. Plasmid isolation and gel extraction kits were from Qiagen. Biacore materials were obtained from GE Healthcare. Retinoid analogues were synthesized by Sygnature Chemical Services. Other reagents used were molecular biology grade.

Expression and Purification of Recombinant Human SRBP in E. coli. The mature form of human sRBP was expressed without tags using vector pMMHa. NdeI and BamHI restriction sites flanking the coding sequence of mature human sRBP (corresponding to residues 19-201) were constructed by PCR using the sRBP cDNA originally cloned into the $\mathrm{pQE}-30$ vector. $^{9}$ The oligonucleotide primers designated to amplify the insert were NdeI (forward) 5 -TACATATGGAGCGCGACTGCCGAGTG-3' and BamHI (reverse) 5'-TAGGATCCCTACAAAAGGTTTCTTTCTGATCTGC-3'. The PCR product was inserted into the pCR-Blunt II TOPO vector, digested with NdeI and BamHI, and introduced into the same restriction sites of the $\mathrm{pMMHa}$ vector under the control of the $\mathrm{T} 7$ promoter.

BL21(DE3) cells transformed with expression plasmid pMMHasRBP were grown in $2 \times Y$ T medium ( $1.6 \%$ tryptone, $1 \%$ yeast extract, and $0.5 \% \mathrm{NaCl}$ ) with $100 \mu \mathrm{g} / \mathrm{mL}$ ampicillin. When the cell culture reached an optical density of 0.6 at $600 \mathrm{~nm}$, protein expression was induced with $1 \mathrm{mM} \mathrm{IPTG}$. After overnight incubation at $37^{\circ} \mathrm{C}$, the cells were harvested by centrifugation at $7000 \mathrm{~g}$ for $10 \mathrm{~min}$ at $4{ }^{\circ} \mathrm{C}$ and subjected to disruption by sonication. The resulting suspension was centrifuged at $10000 \mathrm{~g}$ for $10 \mathrm{~min}$ at $4{ }^{\circ} \mathrm{C}$ and the pellet (sRBP inclusion bodies) suspended at a concentration of $1 \mathrm{mg} / \mathrm{mL}$ sRBP in $5 \mathrm{M}$ guanidinium chloride with $10 \mathrm{mM} \mathrm{DTT}$ at $\mathrm{pH} 9.0$ to help in the reduction and solubilization of recombinant protein. After overnight incubation at $25^{\circ} \mathrm{C}$, the refolding of sRBP was started by dilution of the 
denatured protein to a concentration of $0.25 \mathrm{mg} / \mathrm{mL}$ in cold refolding buffer $[25 \mathrm{mM}$ Tris- $\mathrm{HCl}$ ( $\mathrm{pH}$ 9.0), $0.3 \mathrm{mM}$ cystine, $3 \mathrm{mM}$ cysteine, and $1 \mathrm{mM}$ EDTA] with a 10 -fold molar excess of $\mathrm{ROH} .{ }^{37}$ The guanidinium chloride concentration at this step was $1 \mathrm{M}$. After refolding, the protein solution was dialyzed against PBS buffer, and then refolded sRBP was purified by affinity chromatography with His-TTR (see below).

Expression and Purification of Recombinant Human SRBP in $P$. pastoris. The sRBP was expressed with an $\mathrm{N}$-terminal His tag using the $P$. pastoris expression system as described previously. ${ }^{23}$ The sRBP coding sequence was amplified by PCR using the oligonucleotide primers EcoRI (forward) 5 -GAATTCCATCATCATCATCATCATGAGCGCGACTGCCGAGTG-3' and XbaI (reverse) 5' $5^{\prime}$-TCTAGACTACAAAAGGTTTCTTTCTGATCTGCC- $3^{\prime}$. The forward primer included the sequence for a six-His tag. The PCR product was ligated in the pCR-Blunt II TOPO vector and subsequently introduced into the EcoRI and $\mathrm{XbaI}$ sites of the pPICZ $\alpha$ A vector under the control of the AOX1 promoter.

P. pastoris cells were transformed with expression vector $\mathrm{pPICZ} \alpha$ A-His-sRBP and grown at $30^{\circ} \mathrm{C}$ in phosphate-buffered YP medium $[1 \%$ yeast extract and $2 \%$ peptone ( $\mathrm{pH} 7.5$ )] in the presence of $2 \%$ glycerol $(\mathrm{w} / \mathrm{v})$ until the $\mathrm{OD}_{600}$ reached 6.0. The cells were harvested by centrifugation at $7000 \mathrm{~g}$ for $10 \mathrm{~min}$ and used to inoculate YP medium to an $\mathrm{OD}_{600}$ of 1.0 supplemented with $1 \%$ methanol (v/v) to induce expression. For each of 2 days, methanol was added to a final concentration of $1 \%(\mathrm{v} / \mathrm{v})$. After induction for $48 \mathrm{~h}$, the culture supernatant containing the His-sRBP was incubated with Ni-NTA resin and the bound proteins eluted with elution buffer $\left[20 \mathrm{mM} \mathrm{Na} 2 \mathrm{HPO}_{4}\right.$, $500 \mathrm{mM} \mathrm{NaCl}$, and $250 \mathrm{mM}$ imidazole ( $\mathrm{pH}$ 7.4)]. The purified HissRBP was dialyzed against PBS buffer and then concentrated by ultrafiltration.

Expression and Purification of Recombinant Human His-TTR. The coding sequence of human TTR in vector PMMHa was a gift from J. W. Kelly. ${ }^{38}$ To facilitate the subsequent purification of the holo-sRBPTTR complex, we expressed TTR with an $\mathrm{N}$-terminal His tag. The coding sequence of mature TTR (corresponding to residues 21-147) was inserted into the BamHI and HindIII restriction sites in the pQE-30 vector. The oligonucleotide primers used in the PCR were BamHI (forward) 5'-GGATTCGGCCCTACGGGCACCG-3' and HindIII (reverse) 5'-AAGCTTTCATTCCTTGGGATTGGTGACG-3'. The PCR product was ligated in the pCR-Blunt II TOPO vector, digested with BamHI and HindIII, and inserted into the PQE-30 vector.

The expression of this protein in E. coli was performed as for sRBP. After overnight induction with IPTG, the cells were collected and sonicated. The supernatant containing the soluble TTR was incubated with Ni-NTA resin and the recombinant protein eluted with elution buffer. The purified His-TTR was dialyzed against PBS buffer.

Purification of the ROH-sRBP-TTR Complex. Purified His-TTR was added to the refolded, untagged holo-sRBP solution and the mixture incubated overnight at $4{ }^{\circ} \mathrm{C}$ in the presence of $100 \mu \mathrm{M} \mathrm{ROH}$. Then, the protein solution was applied to a cobalt affinity column equilibrated with buffer I [ $20 \mathrm{mM} \mathrm{Na}_{2} \mathrm{HPO}_{4}, 500 \mathrm{mM} \mathrm{NaCl}$, and $10 \mathrm{mM}$ imidazole ( $\mathrm{pH}$ 7.4)]. The column was washed with the same buffer and then eluted with elution buffer. Fractions were analyzed by SDS-PAGE and Coomassie staining.

Fluorimetric Binding Assays. The binding of compounds to HissRBP was monitored by titration of the intrinsic fluorescence emission of the protein in the presence of increasing concentrations of compounds. The quenching of protein fluorescence due to the transfer of energy to the ligand was evaluated using excitation and emission wavelengths of 280 and $350 \mathrm{~nm}$, respectively, in a Cary Eclipse fluorescence spectrophotometer (Varian). Purified His-sRBP expressed with the $P$. pastoris system was diluted to a concentration of $2 \mu \mathrm{M}$ in PBS buffer, and small increments of compound solutions in ethanol were added. The system was mixed and allowed to equilibrate for $5 \mathrm{~min}$ before the fluorescence emission of the compound-His-sRBP complex was recorded. The final concentration of ethanol never exceeded $2 \%$. A solution of $N$-acetyl-L-tryptophanamide was used as a blank. The apparent dissociation constants $\left(K_{\mathrm{d}}\right)$ of compounds from His-sRBP were estimated as described by Cogan et al. ${ }^{19}$

SRBP-TTR Interaction Assessed by Pull-Down Assay. The capacity of the compounds that bind to sRBP to disrupt the interaction between this protein and its partner TTR was examined first by a pull-down assay. In this assay, the purified holo-sRBP-TTR complex $[0.2 \mathrm{mg} / \mathrm{mL}$ in PBS buffer ( $\mathrm{pH} 7.4)]$ was incubated in the presence of $10 \mu \mathrm{M}$ retinol and each compound at $100 \mu \mathrm{M}$, for $1 \mathrm{~h}$ at $37^{\circ} \mathrm{C}$. Then, $20 \mu \mathrm{L}$ of cobalt resin was added to separate by pull-down assay the fraction of free sRBP from the fraction bound to TTR. The flow-throughs, containing the free sRBP, were examined by SDS-PAGE and silver staining. A control with FEN, which is known to disrupt the interaction between sRBP and TTR, was included in the assay for comparison.

Time-Resolved FRET. The TR-FRET assay was based on the previously published protocol of Coward et al. ${ }^{22}$ The reaction mixtures were prepared in white 96-well plates (Greiner) in a final volume of $100 \mu \mathrm{L}$. Native TTR was biotinylated according to the manufacturer's manual. Each well contained $5 \mathrm{nM}$ apo-His-sRBP, $100 \mathrm{nM}$ biotinylated TTR, $100 \mathrm{nM}$ SureLight streptavidin-conjugated APC, $1 \mathrm{nM}$ europiumlabeled anti-His tag antibody, $10 \mu \mathrm{M}$ inhibitor, and increasing concentrations of $\mathrm{ROH}$ in TR-FRET buffer $[20 \mathrm{mM}$ Tris- $\mathrm{HCl}$ ( $\mathrm{pH} 7.4)$, $150 \mathrm{mM} \mathrm{NaCl}, 1 \mathrm{mM}$ EDTA, $0.01 \% \mathrm{BSA}$, and 0.02\% Tween 20]. Reaction mixtures were incubated for $2 \mathrm{~h}$ at room temperature and measured on a POLARstar Omega microplate reader (excitation wavelength of $337 \mathrm{~nm}$, emission wavelengths of 615 and $665 \mathrm{~nm}$ ).

Surface Plasmon Resonance (SPR). Interaction analyses were performed in SPR running buffer (HBS with $50 \mu \mathrm{M}$ EDTA) at a flow rate of $10 \mu \mathrm{L} / \mathrm{min}$, at a constant temperature $\left(25^{\circ} \mathrm{C}\right)$, using a Biacore 3000 system (GE Healthcare). Ni-NTA sensor chips were used for all experiments, and general procedures were performed according to the manufacturer's instructions for this sensor chip. Briefly, each cycle consisted of surface activation with $20 \mu \mathrm{L}$ of nickel $(2 \mathrm{~min}$ ), followed by a $5 \mathrm{~min}$ injection of recombinant sRBP (His-tagged, $200 \mathrm{nM}$ solution, prepared in SPR running buffer), followed by a 1 min pulse of a specific concentration of compound (diluted in SPR running buffer), culminating with (i) a 5 min injection of untagged, native TTR $(1 \mu \mathrm{M}$ in running buffer incubated with each compound at $10 \mu \mathrm{M}$ ) or (ii) a 5 min injection of solubilized HEK293 cells membranes ${ }^{9}(50 \mu \mathrm{g} / \mathrm{mL}$ in running buffer incubated with each compound at $10 \mu \mathrm{M})$. Finally, sensor chip regeneration was achieved by stripping all proteins from the surface, performing a 2 min injection of $0.3 \mathrm{mM}$ EDTA in HBS, at the end of each cycle (maximal number of regenerations per chip, 100). Sensor chips were used for 2 weeks, or until the level of nonspecific binding increased $(\geq 5 \%)$. All experiments were performed in parallel with an inactivated flow cell not coated with protein. Each independent experiment was repeated three to five times.

Data Processing. Prism 5.00 (GraphPad Software Inc.) was used to determine $\mathrm{EC}_{50}$ values. All SPR sensorgrams were corrected for bufferinduced refractive index changes at an uncoated reference surface, analyzed using BIAEVALUATION version 3.2 (GE Healthcare).

Chemistry. For the determination of compound purity, the system consisted of a Waters HPLC and mass spectrometer system and an Agilent Scalar $5 \mu \mathrm{m} \mathrm{C18} 50 \mathrm{~mm} \times 4.6 \mathrm{~mm}$ column. Detection was achieved using an electrospray ionization source (positive or negative ion) and a UV detector at 254 and $215 \mathrm{~nm}$. Mobile phase A was $0.1 \%$ aqueous formic acid, and mobile phase $\mathrm{B}$ was $0.1 \%$ formic acid in $\mathrm{MeCN}$. The flow rate was $2.5 \mathrm{~mL} / \mathrm{min}$. The following gradient was used: $5 \% \mathrm{~B}$ from 0 to $0.1 \mathrm{~min}, 5$ to $95 \%$ B from 0.1 to $5 \mathrm{~min}, 95 \%$ B from 5 to $5.5 \mathrm{~min}$, $95 \%$ B from 5.5 to $5.6 \mathrm{~min}$, flow rate increased to $3.5 \mathrm{~mL} / \mathrm{min}, 95 \% \mathrm{~B}$ from 5.6 to $6.6 \mathrm{~min}, 95$ to $5 \% \mathrm{~B}$ from 6.6 to $6.75 \mathrm{~min}, 5 \% \mathrm{~B}$ from 6.75 to $6.9 \mathrm{~min}, 5 \% \mathrm{~B}$ from 6.9 to $7 \mathrm{~min}$, flow rate reduced to $2.5 \mathrm{~mL} / \mathrm{min}$. The majority of the library supplied was $>95 \%$ pure. 
Preparation. Retinoic acid $(1 \mathrm{~g}, 3.33 \mathrm{mmol})$ and EDCI $(0.957 \mathrm{~g}, 4.99$ $\mathrm{mmol})$ were stirred in DCM $(20 \mathrm{~mL})$, and methyl 2-(4-aminophenoxy)acetate $(0.724 \mathrm{~g}, 3.99 \mathrm{mmol})$ was added (Scheme 1$)$. After $16 \mathrm{~h}$, the reaction mixture was applied to a silica cartridge $(80 \mathrm{~g})$ and eluted with an EtOAc/isohexane mixture (1:3, v/v) to afford the target compound as a yellow oil that solidifies on standing.

1, methyl 2-\{4-[(2E,4E,6E,8E)-3,7-dimethyl-9-(2,6,6-trimethylcyclohex-1-en-1-yl)nona-2,4,6,8-tetraenamido]phenoxy $\}$ acetate: $t_{\mathrm{R}}=3.02$ $\min ; m / z 464(\mathrm{M}+\mathrm{H})^{+}\left(\mathrm{ES}^{+}\right)$; yield $0.5226 \mathrm{~g}$, 34\%; $100 \%$ pure.<smiles>COC(=O)COc1ccc(NC(=O)/C=C(C)/C=C/C=C(C)/C=C/C2=C(C)CCCC2(C)C)cc1</smiles>

Preparation. 4-Hydroxyaniline $(43.6 \mathrm{mg}, 0.399 \mathrm{mmol})$ was added to a solution of cis-retinoic acid (100 mg, $0.333 \mathrm{mmol})$ and EDCI $(96 \mathrm{mg}$, $0.499 \mathrm{mmol})$ in DCM ( $1 \mathrm{~mL})$ (Scheme 2), and the reaction mixture was stirred at room temperature overnight.

The reaction mixture was diluted with water and passed through a phase separator. The organic layer was applied to a $4 \mathrm{~g}$ silica cartridge and eluted with 0 to $100 \%$ EtOAc in cyclohexane. This gave a yellow solid.

23, (2Z,4E,6E,8E)-N-(4-hydroxyphenyl)-3,7-dimethyl-9-(2,6,6-trimethylcyclohex-1-en-1-yl)nona-2,4,6,8-tetraenamide: $t_{\mathrm{R}}=2.82 \mathrm{~min}$; $m / z 392(\mathrm{M}+\mathrm{H})^{+}\left(\mathrm{ES}^{+}\right)$; yield $13.6 \mathrm{mg}, 10 \%$; $94 \%$ pure.<smiles>CC1=C(/C=C/C(C)=C/C=C/C(C)=C\C(=O)Nc2ccc(O)cc2)C(C)(C)CCC1</smiles>

Preparation. Amine ( $0.4 \mathrm{mmol}, 1.2$ equiv) was added to retinoic acid (100 mg, $0.333 \mathrm{mmol}$ ) and EDCI $(96 \mathrm{mg}, 0.499 \mathrm{mmol})$ in DCM $(1 \mathrm{~mL})$ (Scheme 3). The reaction mixtures were then stirred at room temperature for $24 \mathrm{~h}$. All reactions were investigated by LC-MS. Those showing the desired product were quenched with water, and the mixture was passed through a phase separator. Products were purified by preparative HPLC.

41, (2E,4E,6E,8E)-N-(2,3-dihydroxypropyl)-3,7-dimethyl-9-(2,6,6trimethylcyclohex-1-en-1-yl)nona-2,4,6,8-tetraenamide: $t_{\mathrm{R}}=4.72 \mathrm{~min}$; $\mathrm{m} / z 374(\mathrm{M}+\mathrm{H})^{+}\left(\mathrm{ES}^{+}\right)$; yield $7.8 \mathrm{mg}, 6 \%$; $92 \%$ pure.<smiles>CC1=C(/C=C/C(C)=C/C=C/C(C)=C/C(=O)NCC(O)CO)C(C)(C)CCC1</smiles>

48, (2E,4E,6E,8E)-N-(2-hydroxyethyl)-3,7-dimethyl-9-(2,6,6-trimethylcyclohex-1-en-1-yl)nona-2,4,6,8-tetraenamide: $t_{\mathrm{R}}=2.60 \mathrm{~min} ; \mathrm{m} / z 344$ $(\mathrm{M}+\mathrm{H})^{+}\left(\mathrm{ES}^{+}\right)$; yield $12.2 \mathrm{mg}, 11 \%$; $90 \%$ pure.<smiles>CC1=C(/C=C/C(C)=C/C=C/C(C)=C/C(=O)NCCO)C(C)(C)CCC1</smiles>

Amine (0.4 mmol, 1.2 equiv) was added to Retinoic acid (100 mg, $0.333 \mathrm{mmol}$ ), and EDCI (96 mg, $0.499 \mathrm{mmol})$ in DCM ( $1 \mathrm{~mL})$. The reaction mixtures were then stirred at room temperature for $24 \mathrm{~h}$. All reactions were investigated by LC-MS. Those showing the desired product were quenched with water, and the mixture was passed through a phase separator.

All products were purified on $4 \mathrm{~g}$ silica cartridges eluting with a 0 to $100 \%$ gradient ( $5 \% \mathrm{MeOH}$ in EtOAc) in isohexane.
58, (2E,4E,6E,8E)-N-[4-(dimethylamino)phenyl]-3,7-dimethyl9-(2,6,6-trimethylcyclohex-1-en-1-yl)nona-2,4,6,8-tetraenamide: $t_{\mathrm{R}}=$ $3.22 \mathrm{~min} ; \mathrm{m} / z 419(\mathrm{M}+\mathrm{H})^{+}\left(\mathrm{ES}^{+}\right)$; yield $15.3 \mathrm{mg}, 11 \%$; $91 \%$ pure.<smiles>CC1=C(/C=C/C(C)=C/C=C/C(C)=C/C(=O)Nc2ccc(N(C)C)cc2)C(C)(C)CCC1</smiles>

62, (2E,4E,6E,8E)-3,7-dimethyl-1-morpholino-9-(2,6,6-trimethylcyclohex-1-en-1-yl)nona-2,4,6,8-tetraen-1-one: $t_{\mathrm{R}}=3.09 \mathrm{~min} ; \mathrm{m} / \mathrm{z} 370$ $(\mathrm{M}+\mathrm{H})^{+}\left(\mathrm{ES}^{+}\right)$; yield $10.8 \mathrm{mg}, 9 \%$; $98 \%$ pure.<smiles>CC1=C(/C=C/C(C)=C/C=C/C(C)=C/C(=O)N2CCOCC2)C(C)(C)CCC1</smiles>

\section{ASSOCIATED CONTENT}

S Supporting Information. Chemical structures of compounds $1-68$. This material is available free of charge via the Internet at http://pubs.acs.org.

\section{AUTHOR INFORMATION}

\section{Corresponding Author}

*E-mail: j.b.c.findlay@leeds.ac.uk or John.Findlay@nuim.ie. Phone: +44(0)113 34 33140. Fax: +353 17086369.

\section{ACKNOWLEDGMENT}

This work was supported by the Marie Curie Transfer of Knowledge Scheme (MTKD-CT-2006-042480) and an Enterprise Ireland proof of concept (POC) grant (PC-2007-047). G.K.K. acknowledges the support of an Irish Research Council for Science, Engineering and Technology (IRCSET) postdoctoral fellowship (PD-2008-28). We acknowledge the SFI/HEA Irish Centre for High-End Computing (ICHEC), the NUIM HPC centre, and the HEA Trinity Centre for High Performance Computing (TCHPC) for the provision of computational facilities and support. We sincerely thank the software vendors for their continuing support for such academic research efforts, in particular contributions from Openeye Scientific, Scitegic, and the Chemical Computing Group.

\section{ABBREVIATIONS USED}

APC, allophycocyanin; FEN, Fenretinide; ROH, retinol; RU, resonance unit; SDS-PAGE, sodium dodecyl sulfate-polyacrylamide gel electrophoresis; SPR, surface plasmon resonance; sRBP, serum retinol-binding protein; TR-FRET, time-resolved fluorescence resonance energy transfer; TTR, transthyretin

\section{REFERENCES}

(1) Zanotti, G.; Folli, C.; Cendron, L.; Alfieri, B.; Nishida, S.; Gliubich, F.; Pasquato, N.; Negro, A.; Berni, R. Structural and mutational analyses of protein-protein interactions between transthyretin and retinol-binding protein. FEBS J. 2008, 275, 5841-5854.

(2) Kanai, M.; Raz, A.; Goodman, D. Retinol-binding protein: The transport protein for vitamin A in human plasma. J. Clin. Invest. 1968, 47, 2025-2044.

(3) Wolf, G. Multiple functions of vitamin A. Physiol. Rev. 1984, 64, 873-937. 
(4) Cowan, S.; Newcomer, M.; Jones, T. Crystallographic refinement of human serum retinol binding protein at $2 \AA$ resolution. Proteins 1990, 8, 44-61.

(5) Monaco, H.; Rizzi, M.; Coda, A. Structure of a complex of two plasma proteins: Transthyretin and retinol-binding protein. Science 1995, 268, 1039-1041.

(6) Goodman, D. Overview of current knowledge of metabolism of vitamin A and carotenoids. J. Natl. Cancer Inst. 1984, 73, 1375-1379.

(7) Kawaguchi, R.; Yu, J.; Honda, J.; Hu, J.; Whitelegge, J.; Ping, P.; Wiita, P.; Bok, D.; Sun, H. A membrane receptor for retinol binding protein mediates cellular uptake of vitamin A. Science 2007, 315, $820-825$.

(8) Kawaguchi, R.; Yu, J.; Wiita, P.; Honda, J.; Sun, H. An essential ligand-binding domain in the membrane receptor for retinol-binding protein revealed by large-scale mutagenesis and a human polymorphism. J. Biol. Chem. 2008, 283, 15160-15168.

(9) Redondo, C.; Vouropoulou, M.; Evans, J.; Findlay, J. Identification of the retinol-binding protein (RBP) interaction site and functional state of RBPs for the membrane receptor. FASEB J. 2008, 22, $1043-1054$.

(10) Sivaprasadarao, A.; Sundaram, M.; Findlay, J. Interactions of retinol-binding protein with transthyretin and its receptor. Methods Mol. Biol. 1998, 89, 155-163.

(11) Yang, Q.; Graham, T.; Mody, N.; Preitner, F.; Peroni, O.; Zabolotny, J.; Kotani, K.; Quadro, L.; Kahn, B. Serum retinol binding protein 4 contributes to insulin resistance in obesity and type 2 diabetes. Nature 2005, 436, 356-362.

(12) Graham, T.; Yang, Q.; Blüher, M.; Hammarstedt, A.; Ciaraldi, T.; Henry, R.; Wason, C.; Oberbach, A.; Jansson, P.; Smith, U.; Kahn, B. Retinol-binding protein 4 and insulin resistance in lean, obese, and diabetic subjects. N. Engl. J. Med. 2006, 354, 2552-2563.

(13) Ost, A.; Danielsson, A.; Lidén, M.; Eriksson, U.; Nystrom, F.; Stralfors, P. Retinol-binding protein-4 attenuates insulin-induced phosphorylation of IRS 1 and ERK1/2 in primary human adipocytes. FASEB J. 2007, 21, 3696-3704.

(14) Zanardi, S.; Serrano, D.; Argusti, A.; Barile, M.; Puntoni, M.; Decensi, A. Clinical trials with retinoids for breast cancer chemoprevention. Endocr. Relat. Cancer 2006, 13, 51-68.

(15) Radu, R.; Han, Y.; Bui, T.; Nusinowitz, S.; Bok, D.; Lichter, J.; Widder, K.; Travis, G.; Mata, N. Reductions in serum vitamin A arrest accumulation of toxic retinal fluorophores: A potential therapy for treatment of lipofuscin-based retinal diseases. Invest. Ophthalmol. Visual Sci. 2005, 46, 4393-4401.

(16) Zanotti, G.; Marcello, M.; Malpeli, G.; Folli, C.; Sartori, G.; Berni, R. Crystallographic studies on complexes between retinoids and plasma retinol-binding protein. J. Biol. Chem. 1994, 269, 29613-29620.

(17) Berni, R.; Formelli, F. In vitro interaction of fenretinide with plasma retinol-binding protein and its functional consequences. FEBS Lett. 1992, 308, 43-45.

(18) Preitner, F.; Mody, N.; Graham, T.; Peroni, O.; Kahn, B. Longterm Fenretinide treatment prevents high-fat diet-induced obesity, insulin resistance, and hepatic steatosis. Am. J. Physiol. 2009, 297, E1420-E1429.

(19) Cogan, U.; Kopelman, M.; Mokady, S.; Shinitzky, M. Binding affinities of retinol and related compounds to retinol binding proteins. Eur. J. Biochem. 1976, 65, 71-78.

(20) MOE (2008) Chemical Computing Group.

(21) Malpeli, G.; Folli, C.; Berni, R. Retinoid binding to retinolbinding protein and the interference with the interaction with transthyretin. Biochim. Biophys. Acta 1996, 1294, 48-54.

(22) Coward, P.; Conn, M.; Tang, J.; Xiong, F.; Menjares, A.; Reagan, J. Application of an allosteric model to describe the interactions among retinol binding protein 4 , transthyretin, and small molecule retinol binding protein 4 ligands. Anal. Biochem. 2009, 384, 312-320.

(23) Wysocka-Kapcinska, M.; Campos-Sandoval, J.; Pal, A.; Findlay, J. Expression and characterization of recombinant human retinolbinding protein in Pichia pastoris. Protein Expression Purif. 2010, 71, $28-32$.
(24) Redondo, C.; Burke, B.; Findlay, J. The retinol-binding protein system: A potential paradigm for steroid-binding globulins? Horm. Metab. Res. 2006, 38, 269-278.

(25) Sivaprasadarao, A.; Findlay, J. The interaction of retinol-binding protein with its plasma-membrane receptor. Biochem. J. 1988, $255,561-569$.

(26) Cho, Y.; Youn, B.; Lee, H.; Lee, N.; Min, S.; Kwak, S.; Lee, H.; Park, K. Plasma retinol-binding protein- 4 concentrations are elevated in human subjects with impaired glucose tolerance and type 2 diabetes. Diabetes Care 2006, 29, 2457-2461.

(27) Craig, R.; Chu, W.; Elbein, S. Retinol binding protein 4 as a candidate gene for type 2 diabetes and prediabetic intermediate traits. Mol. Genet. Metab. 2007, 90, 338-344.

(28) Gavi, S.; Stuart, L.; Kelly, P.; Melendez, M.; Mynarcik, D.; Gelato, M.; McNurlan, M. Retinol-binding protein 4 is associated with insulin resistance and body fat distribution in nonobese subjects without type 2 diabetes. J. Clin. Endocrinol. Metab. 2007, 92, 1886-1890.

(29) Graham, T.; Wason, C.; Blüher, M.; Kahn, B. Shortcomings in methodology complicate measurements of serum retinol binding protein (RBP4) in insulin-resistant human subjects. Diabetologia 2007, $50,814-823$.

(30) Lee, D.; Lee, J.; Im, J. Association of serum retinol binding protein 4 and insulin resistance in apparently healthy adolescents. Metabolism 2007, 56, 327-231.

(31) Janke, J.; Engeli, S.; Boschmann, M.; Adams, F.; Böhnke, J.; Luft, F.; Sharma, A.; Jordan, J. Retinol-binding protein 4 in human obesity. Diabetes 2006, 55, 2805-2810.

(32) Takashima, N.; Tomoike, H.; Iwai, N. Retinol-binding protein 4 and insulin resistance. N. Engl. J. Med. 2006, 355, 1392, author reply $1394-1395$

(33) Manolescu, D.; Sima, A.; Bhat, P. All-trans retinoic acid lowers serum retinol-binding protein 4 concentrations and increases insulin sensitivity in diabetic mice. J. Nutr. 2010, 140, 311-316.

(34) Noy, N.; Xu, Z. Interactions of retinol with binding proteins: Implications for the mechanism of uptake by cells. Biochemistry 1990, 29, 3878-3883.

(35) Berni, R.; Clerici, M.; Malpeli, G.; Cleris, L.; Formelli, F. Retinoids: In vitro interaction with retinol-binding protein and influence on plasma retinol. FASEB J. 1993, 7, 1179-1184.

(36) Johansson, H.; Gandini, S.; Guerrieri-Gonzaga, A.; Iodice, S.; Ruscica, M.; Bonanni, B.; Gulisano, M.; Magni, P.; Formelli, F.; Decensi, A. Effect of fenretinide and low-dose tamoxifen on insulin sensitivity in premenopausal women at high risk for breast cancer. Cancer Res. 2008, 68, 9512-9518.

(37) Xie, Y.; Lashuel, H.; Miroy, G.; Dikler, S.; Kelly, J. Recombinant human retinol-binding protein refolding, native disulfide formation, and characterization. Protein Expression Purif. 1998, 14, 31-37.

(38) Lashuel, H.; Wurth, C.; Woo, L.; Kelly, J. The most pathogenic transthyretin variant, L55P, forms amyloid fibrils under acidic conditions and protofilaments under physiological conditions. Biochemistry 1999, $38,13560-13573$.

(39) DeLano, W. L. (2002) The PyMOL Molecular Graphics System, DeLano Scientific, Palo Alto, CA. 